\title{
Um estudo de caso: programas computacionais mediando o ensino de isomeria geométrica
}

\author{
Fabiana Pauletti \\ fabiana.pauletti@acad.pucrs.br \\ 0000-0001-5896-5110 \\ Doutoranda do Programa de Pós- \\ Graduação em Educação em \\ Ciências e Matemática pela \\ Pontifícia Univ ersidade Católica do \\ Rio Grande do Sul (PUCRS) \\ Francisco Catelli \\ catelli@ucs.br \\ 0000-0002-2484-7711 \\ Prof essor do Programa de Pós- \\ Graduação em Educação em \\ Ciências e Matemática da \\ Univ ersidade de Caxias do Sul \\ (UCS)
}

\begin{abstract}
RESUMO
Este artigo tem por objetivo investigar as possibilida des de uso dos programas de simulação computacional no ensino de Química e especificamente no campo de isomeria geométrica no contexto do ensino público. O estudo foi constituído a partir de uma pesquisa bibliográfica e de um estudo de caso numa escola pública, na qual foram realizadas entrevistas semiestruturadas com três professores de Química. A metodologia empregada foi a Análise Textual Discursiva. Os resultados mostram que o ensino de isomeria geométrica pode ser potencializado com o uso de aplicativos computacionais, numa dimensão em que os níveis de representação macroscópico, microscópico e simbólico são explorados a partir da multiplicidade de simulações suscitadas nesses aplicativos.
\end{abstract}

PALAVRAS-CHAVE: Ensino de Química. Isomeria geométrica. Programas computacionais . 


\section{INTRODUÇÃO}

O nível de desenvolvimento tecnológico pelo qual a sociedade vem passando implica em um grande número de processos de transição. Um desses processos diz respeito à passagem da tecnologia analógica para a digital (BIANCHETTI, 2001). Nesse cenário, as barreiras de tempo e espaço são gradativamente superadas em virtude do avanço e disseminação das tecnologias da informação e comunicação. Segundo Almeida e Valente (2011), a evolução dessas tecnologias al tera os modos de ser e estar no mundo e reconfigura as relações comunicacionais, emergindo assim um novo perfil de sociedade impregnado de tecnologia digital.

Em decorrência, competeà escola e aos professores considerar as tecnologias digitais (TDs) como instrumento para auxiliar o aprendizado dos estudantes e para incrementar as práticas educativas, visto que a tecnologia circula de forma intensa, aberta e universal (CHARTIER, 2007). É inconteste o fato de que foram abertas novas possibilidades de ensino através do emprego das TDs, principalmente mediante o uso de programas computacionais. Um uso didático dessas ferramentas digitais pode potencializar o ensino de Química, e de maneira mais pontual, o ensino de isomeria geométrica, por conta do caráter essencialmente abstrato do tema. Um dos interesses deste trabalho é destacar a relevância de tratar os níveis representacionais do conhecimento químico, transformando os programas computacionais em potentes ferramentas para essa abordagem. Diversos autores da área afirmam que os níveis de representação (macroscópico, microscópico e simbólico) são essenciais para ensinar e aprender Química. Mas, além de compreendê-los é fundamental transitar entre eles, e é condição essencial que o ensino de Química, além de abrigar esses níveis, acolha uma multiplicidade de representações a fim de favorecer a aprendizagem (WU; SHAH, 2004). Uma consulta à literatura da área indica a existência de um consenso sobre a relevância de proliferar as formas de representação em amplitude máxima, como também promover a livre transição entre os três níveis de representação, com vistas a um ensino de Química genuíno.

Neste sentido, percebe-se a natureza abstrata da Química e o que se evidencia é que, para explorar os fenômenos químicos, faz-se necessário trabalhar com modelos mentais, concretos ou virtuais para representar determinados fenômenos inacessíveis à percepção humana (FERREIRA; ARROIO; REZENDE, 2011), principalmente quando os fenômenos são tratados em nível microscópico. Assim sendo, quando a Química é abordada nesse nível, as TDs, mais especificamente os programas computacionais, podem ser ferramentas essenciais para modelização ou representação dos fenômenos químicos, prestando-se, assim, à fabricação de novas condições que permitam aos estudantes compreenderem em profundidade tais fenômenos. Muitos pesquisadores e educadores têm empregado modelos e ferramentas tecnológicas digitais a fim de superar as mais diversas dificuldades na representação da Química, sobretudo quando é abordada em nível microscópico.

O problema que originou o presente estudo é: Como os recursos tecnológicos digitais (programas computacionais) podem ser usados no ensino de isomeria geométrica? Para construir respostas para esse problema no primeiro bloco será abordada uma concepção de ensino e de aprendizagem particular, no intuito de corporificar nossa escolha e permitir argumentar que a comunhão do ensino de

Página | 251 
Química (aqui, a isomeria geométrica) com os aplicativos computacionais pode resultar numa união muito fecunda. No segundo bloco, trataremos de algumas peculiaridades da Química, e de alguns obstáculos que se impõe à compreensão desta ciência, bem como a relevância de aprender Química. Após será apresentado o estudo de caso realizado com três professores de Química, as categorias oriundas desta investigação e, por fim, nossas considerações finais.

\section{DELINEANDO UMA PERSPECTIVA DE ENSINO}

Dado que esse estudo trata de questões relacionadas ao ensino de Química, mais especificamente da isomeria geométrica, a concepção de ensino subjacente deve ser elucidada. $\mathrm{O}$ interacionismo fundamenta e legitima os processos de ensinar e de aprender, tais como concebidos e apresentados nesse estudo, bem como reconhece que, a partir do uso de programas computacionais no ensino, abre-se a possibilidade de promover a aprendizagem. Pretendemos então ao longo deste estudo aclarar nossos ideais de ensino de Química e tratar de suas particularidades, destacando em quais aspectos ela difere de outras ciências. Veremos que a exploração da tecnologia digital no contexto de ensino pode diluir alguns dos entraves que surgem ao ensinar e aprender Química; essa diluição advém em especial da interação que se estabelece entre os estudantes.

Apesar de Vygotsky (1896-1934) nunca ter direcionado o foco de seus escritos à Educação, obteve excepcional mérito ao destacar o viés social do ensino e da aprendizagem, e isso numa época em que nem de longe se imaginava a revolução que estava por vir; no que diz respeito às possibilidades de interação ${ }^{1}$ e comunicação propiciadas principalmente por meio das TDs. Cabe destacar que não existe aqui a pretensão de abranger os (muitos) detalhes da teoria deste autor, o que se pretende é explorar alguns de seus elementos-chave de modo a melhor compreender como a interação dos estudantes com as mais diversas ferramentas pode resultar num processo de aprendizagem. Moreira (2011) explica que, na perspectiva vygotskyana, é por meio da interação social que o indivíduo se apropria do conhecimento culturalmente construído. Diz, ainda, que a interação social implica num certo grau de bidirecionalidade e reciprocidade entre dois ou mais indivíduos, sob a forma de um intercâmbio mais ou menos intenso de informações.

Considerando então a inconteste penetrabilidade das TDs na sociedade atual, que se manifesta (entre outras formas) pela multiplicação das formas de acesso à informação, percebe-se que surgem novos estilos de pensar e raciocinar, e esses estilos colaboram diretamente com o processo de construção de conhecimento, nutrindo-o e potencializando-o (MORAES, 2002). E, dado que a exploração das TDs pode serfeita em grande parte pelos próprios estudantes, aliando a autonomia na liberdade de explorar à possibilidade de troca com os colegas dos resultados dessas explorações, destacamos que a escola pode e deve explorar essas

\footnotetext{
1 Segundo o Dicionário Aurélio, a interação é estabelecida entre duas ou mais pessoas, ou coisas e a relação ou ação é recíproca, isto é, mútua (FERREIRA, 1975). Nesse sentido, entendemos a interação à luz da definição do Dicionário Aurélio: interação é uma ação recíproca entre pessoas ou coisas.
}

Página | 252 
possibilidades de ensino e de aprendizagem a fim de fomentar um ambiente de construção social do conhecimento (VYGOTSKI, 1998).

Pode-se dizer que as TDs e os artefatos que delas emergem são construídos e herdados do meio social em que vivemos. Por extensão, essas tecnologias, tão habilmente manuseadas por parte significativa da comunidade, não podem e não devem ser ignoradas no contexto escolar. Assim sendo, entendemos que a aprendizagem é um processo de construção arquitetado e concretizado por meio da interação, que pode ocorrer tanto a partir da presença de um professor quanto da relação do estudante com um instrumento culturalmente herdado, neste caso, o computador. A interação é permanente - alguém ensina e alguém aprende, mas para que a construção do conhecimento químico possa ocorrer é necessária somente a presença do outro (professor ou não), e é neste momento que é imprescindível a imersão do estudante no seu contexto social, mediante uma interação intensa com esse meio (VYGOTSKI, 1998; VYGOTSKI; LURIA; LEONTIEV, 2001).

Apesar de os argumentos apresentados apontarem - ao nosso ver - para uma concepção interacionista, é certo que essa opção não exclui o legado que outros pontos de vista nos oferecem. É óbvio que outras perspectivas de algum modo contemplam os aspectos que se quer capturar do ponto de vista da penetrabilidade das TDs. Entretanto, nenhuma parece ser tão abrangente como é a concepção interacionista no que diz respeito aos cenários radicalmente novos, abertos pela verdadeira explosão ocorrida no âmbito da informação e comunicação.

\section{UMA BREVE CONSTEXTUALIZAÇÃO DA QUÍMICA}

A Química estuda muitos dos elementos que compõem a imagem do mundo em que vivemos. Para Oliveira, Gouveia e Quadros (2009), o conhecimento químico pode proporcionar ao estudante um entendimento adicional do mundo material e dos fenômenos que nele ocorrem e, por extensão, pode auxiliá-lo a entender alguns dos acontecimentos corriqueiros do seu dia a dia. Logo, o conhecimento químico poderia auxiliar o estudante na tarefa de elaborar uma compreensão da natureza e suas transformações, incluindo-se aí as ações do próprio ser humano na sociedade, através da produção de instrumentos culturais, forjados especialmente a partir de interações sociais. Um entendimento mais agudo de aspectos que afetam diretamente os cidadãos também seria possível: a ação medicinal das drogas, a energia proveniente de usinas nucleares ou hidrelétricas, a evolução do efeito estufa, a degradação do ambiente através de poluentes, são exemplos ilustrativos.

Resumidamente, o conhecimento químico representa uma preciosa condição para o desenvolvimento de um indivíduo habilitado a interpretar as diversas informações advindas da tradição cultural, do meio social e da própria escola. 0 conhecimento químico pode auxiliar na formação de um estudante crítico, disposto a compreender os efeitos que a Química ocasiona no meio em que está inserido; tais informações podem propiciar ao estudante uma participação ativa na sociedade a partir de uma tomada autônoma de decisões (SANTOS; SCHNETZLER, 2000). Visto a relevância do conhecimento químico para a formação 
dos indivíduos, é necessário questionar: quais são as principais dificuldades para ensinar e aprender Química? Quais os caminhos para potencializar este ensino?

$\mathrm{Na}$ literatura relativa ao ensino de Química, encontra-se a menção a alguns obstáculos que muitas vezes "esterilizam" a aprendizagem. Pozo e Crespo (2009) chamam a atenção para o obstáculo que talvez seja o mais importante, a saber, a natureza altamente abstrata da Química. Os autores ressaltam que a dificuldade na aprendizagem em Química pode ocorrer devidoà necessidade de os estudantes compreenderem e analisarem as propriedades e transformações da matéria. Mas para conseguir isso, os estudantes se defrontam com um grande número de leis e conceitos, novos e altamente abstratos, além de ter que estabelecer conexões entre esses conceitos e os fenômenos estudados. Adicionalmente, deparam-se com a necessidade de utilizar uma linguagem simbólica formalizada em alto grau, eventualmente junto com modelos analógicos que ajudam a representar aquilo que não é observável. Desse modo, ainda segundo os autores, justifica-se a afirmação de que um dos maiores obstáculos que o ensino da Química enfrenta é a presença maciça de abstrações, e mesmo de abstrações sobre abstrações. Então, a aprendizagem implica, por um lado, compreender as formas abstratas da Química, de natureza particulada e não observável e, por outro lado, impõe-se a necessidade de rápida transferência de determinadas representações para outras formas e modelos (POZO; CRESPO, 2009). No entanto, ao que tudo indica, a dificuldade aumenta quando a Química é abordada simultaneamente em nível microscópico e em nível simbólico, pois ambas estão fora do universo conceitual do estudante.

De modo semelhante, Souza e Cardoso (2008) alegam que a dificuldade do ensino e na aprendizagem em Química ocorre pela falta de compreensão e domínio do universo macroscópico, simbólico e microscópico; é essencial, segundo eles, a livre transição entre esses três níveis para a construção do conhecimento químico. Johnstone (1982) apresentou um modelo sal ientando as diferenças entre as formas de representação do conhecimento químico e, examinando a literatura, foi possível encontrar vários trabalhos relativos ao ensino e aprendizagem em Química que indicam a existência de um consenso quanto às formas de representação desse conhecimento (GABEL, 1993; GIORDAN; GÓIS, 2005; WU; KRAJCIK; SOLOWAY, 2001).

Em síntese, as possibilidades de representação do conhecimento químico circulam entre os níveis macroscópico, microscópico e simbólico; o nível macroscópico diz respeito aos fenômenos e processos químicos observáveis e perceptíveis numa dimensão visível. O nível simbólico envolve as fórmulas, equações químicas e estruturas, dentre outras. O nível microscópico, por sua vez, envolve os movimentos e arranjo de moléculas, átomos ou partículas (WU; KRAJCIK; SOLOWAY, 2001).

Consultas à literatura permitem diagnosticar que as dificuldades mais significativas na construção do conhecimento químico ocorrem em nível microscópico, em virtude de essa representação ser essencialmente abstrata (GIORDAN; GÓIS, 2005; PAULETTI; CATELLI, 2013; POZO; CRESPO, 2009). A compreensão da Química esbarra no nível microscópico, e isso muitas vezes impede pura e simplesmente a construção desse conhecimento. Em decorrência disso, no próximo bloco, serão abordados alguns estudos que empregaram 
programas computacionais como ferramentas de visualização e de interação no ensino de Química.

\section{RELATOS DE EXPERÊNCIAS COM O USO DE PROGRAMAS COMPUTACIONAIS NO ENSINO DE QUÍMICA}

O uso de alguns programas computacionais ${ }^{2}$ no ensino de Química pode incontestavelmente potencializar o processo de ensino e de aprendizagem, haja vista o caráter dinâmico e a margem de interação forjados nas simulações computacionais, o que estimula o estudante a construir e desenvolver as atividades propostas pelo professor, além de permitir-lhe incalculáveis explorações autônomas. A principal vantagem encontra-se na possibilidade de os estudantes obterem resultados imediatos, decorrentes da modificação de situações e condições, além de minimizar as dificuldades da aprendizagem (EICHLER; DEL PINO, 2000; FERREIRA; ARROIO; REZENDE, 2011; GIORDAN; GÓIS, 2005; WU; SHAH, 2004).

Em recente estudo, foram exploradas algumas possibilidades de representação da Química mediante as tecnologias (PAULETTI; CATELLI, 2013) e, dentre outros aspectos destacou-se o fato de que as TDs podem contribuir significativamente no ensino de Química, na medida em que possibilitam uma vasta gama de representações das formas abstratas, o que, aos olhos de Wu e Shah (2004), é condição necessária para a construção do conhecimento químico. Muitas pesquisas voltadas ao ensino de Química com o uso de programas educacionais vêm sendo realizadas, mas aqui faz-se necessário delimitar. Por isso, dentre muitas, vamos destacar duas, que se coadunam com nosso foco de estudo.

Raupp (2010), investigou o impacto do uso de modelos tridimensionais computacionais no processo de aprendizagem do conceito de isomeria geométrica com estudantes de nível médio e superior. Para a investigação, a autora utilizou o programa de representação molecular ChemSketch ${ }^{3}$, que oferece (entre outras) a possibilidade de formar imagens tridimensionais que permitem notar a diferença entre os isômeros geométricos. Os resultados da pesquisa desenvolvida mostram evidências favoráveis quanto à exploração de modelos tridimensionais no processo de aprendizagem em Química. A autora afirma que a capacidade de raciocínio visuoespacial ${ }^{4}$ dos estudantes pode ser melhorada com o uso de programas educacionais que permitem a construção de modelos moleculares computacionais, auxiliando-os a desenvolverem a capacidade de representar tridimensionalmente os isômeros geométricos. Vale aqui destacar que a habilidade visuoespacial é imprescindível para transitar entre os níveis de representação.

Raupp, Serrano e Moreira (2009, p. 66) explicam que "a habilidade necessária para promover a transformação entre representações 2D e 3D, por exemplo, é

2 Uma listagem contendo diversos programas educacionais comumente empregados no ensino de Química, pode ser encontrada em Santos, Wartha e Filho (2010). Em: http://www.xveneq2010.unb.br/resumos/R0981-1.pdf.

3 ChemSketch é um programa livre que propicia a construção de modelos moleculares bidimensionais e tridimensionais. Maiores informações sobre o programa computacional podem ser encontradas no endereço eletrônico a seguir. Em: http://www.a cdlabs.com.

${ }^{4}$ Raupp (2010, p. 12) nos ensina que "[...] as habilidades espaciais são formadas por um conjunto de fatores, sendo um deles a visualização es pacial (daí o termo visuoespacial), que utiliza uma sequência complexa de manipulação mental para a resolução de problemas". Página | 255 
chamada de habilidade visuoespacial - derivada do conceito visualização espacial [...]". Os autores argumentam ainda que a habilidade visuoespacial liga-se diretamente à transição entre os diferentes níveis de representação de qualquer fenômeno químico. Com isso, neste estudo, o papel que o programa desempenha na compreensão da isomeria geométrica é decisivo, pois auxilia os estudantes no desenvolvimento dessa habilidade que parece ser essencial para representar qualquer fenômeno químico.

Em outro estudo realizado com o uso de programas computacionais no ensino da Química, Giordan e Góis (2005) utilizaram o aplicativo computacional Construtor $^{5}$. O referido programa possibilita a criação de objetos moleculares virtuais bidimensionais que projeta animações e também propicia interfaces de criação e simulação tridimensionais a partir de qualquer fórmula química, seja ela extensa ou condensada, a fim de explorar representações de partículas. Para os autores, o uso desse recurso favorece e estreita a correlação entre as imagens mentais e as representações simbólicas, assim como dos objetos moleculares virtuais e concretos, o que contribui para a aprendizagem e aprofundamento dos conceitos estudados. Uma síntese, feita pelos autores, diz que os estudantes demonstram atitudes positivas, que vão desde o desenvolvimento das atividades propostas pelo professor até a utilização do programa computacional, envolvendo inclusive os estudantes que habitual mente não costumavam participar. Esse é mais um indício de que o uso de programas educacionais, além de potencializar o processo de ensino e de aprendizagem em Química, propicia a motivação e empenho do estudante.

Esses estudos retratam bem as contribuições do uso de programas computacionais no ensino de Química, demonstrando que esses recursos digitais podem ser uma alternativa viável na diluição das dificuldades impostas pela navegação entre os três níveis de representação do conhecimento químico. Além disso, são propiciadas inúmeras formas adicionais de representação e visual ização do nível microscópico, ajudando, desse modo, a superar uma das maiores dificuldades na construção do conhecimento, a saber; a navegação pelo nível microscópico.

O uso de aplicativos computacionais torna-se uma ferramenta efetiva na medida que fornece significativa margem de interação do estudante com o aplicativo contribuindo dessa forma com a aprendizagem desse sujeito. Mas o ponto nevrálgico diz respeito à visualização fomentada nesses programas, pois, sendo a Química uma ciência abstrata (RAUPP, 2010) e sendo precisamente esse um dos principais empecilhos à aprendizagem, é na possibilidade de visualização da abstração química (nível microscópico) que os aplicativos computacionais podem ser decisivos. Com isso, no próximo bloco vamos tratar em particular desses dois aspectos por meio do uso de um aplicativo computacional.

\section{O PROGRAMA COMPUTACIONAL CHEMSKETCK NO ENSINO DA QUÍMICA}

${ }^{5}$ Construtor é um programa que propicia, dentre outras coisas, a criação de objetos moleculares virtuais. Maiores informações s obre o programa computacional podem ser encontradas no endereço eletrônico a seguir. Em: http://objetoseducacionais2.mec.gov.br/handle/mec/3786.

Página | 256 
A possibilidade de visualização dos fenômenos inacessíveis à percepção humana é real mente fascinante. Entretanto, o fascínio pode tornar-seainda maior quando um aplicativo computacional propicia a visualização em três dimensões juntamente com a possibilidade de rotacionar moléculas. É evidente que não bastaria ao estudante entender apenas um dos níveis de representação da Química - o simbólico - para compreender esse conteúdo. Faz-se necessário entender a fórmula molecular ou estrutural (nível simbólico) e compreender a representação dessa estrutura distribuída no espaço, num plano tridimensional.E é nesse caso que surge talvez a oportunidade mais valiosa para a efetivação da transposição da representação bi dimensional (2D) para a tridimensional (3D). Para ilustrar, vamos anal isar duas formas de representação de um isômero geométrico. A Figura 1 é uma representação em forma 2D e é comumente a mais empregada para ensinar este conteúdo; é geralmente encontrada dessa forma nos livros didáticos ${ }^{6}$. O composto "a" é denominado butano, já o composto "b" é o 2metilpropano.

Figura 1 -Representação estrutural plana: a) butano; b) 2-metilpropano.

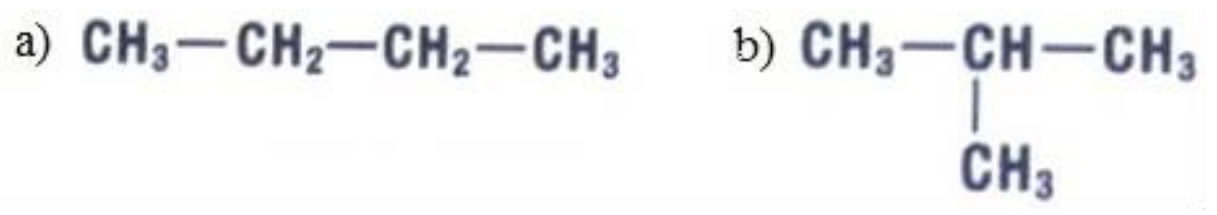

Fonte: Santos e Mól (2005, p. 349)

Já a Figura 2 é um "desenho" dessas mesmas estruturas, produzido pelos autores deste estudo a partir de um aplicativo computacional ${ }^{7}$.

Figura 2 -Representação espacial: a) butano; b) 2-metilpropano.
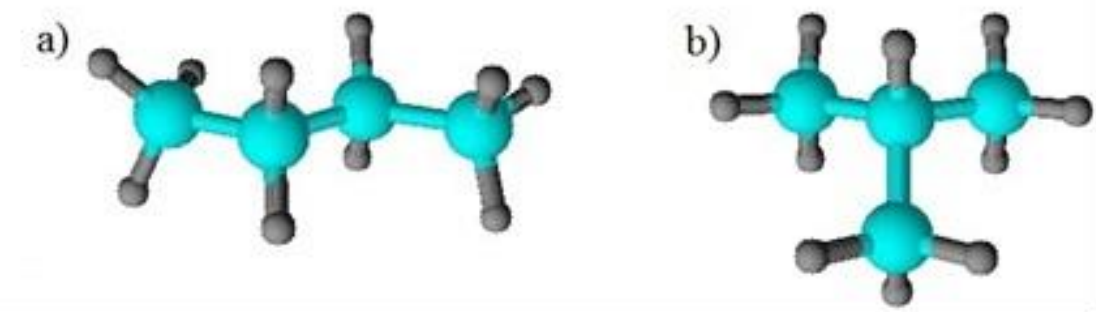

Fonte: Programa computacional ChemSketck (2013)

A vantagem da representação em três dimensões é descrita por Raupp:

A evolu ção histórica das representações trouxe consigo a necessidade de uma muda nça na forma de enxergar o universo microscópico. Estruturas 2D foram substituídas por estruturas em 3D e representadas por meio de projeções ou

\footnotetext{
6 Uma consulta nos Iivros didáticos (NOVAIS, 1993; PERUZZO; CANTO, 1996; SANTOS; MÓL, 2005; FONSECA, 2001; PERUZZO; CANTO, 2006) mos tra que, a partir do a no 2000, a proximadamente, os livros di dáticos começaram a representar as moléculas emtrês dimensões. Antes disso, a representação das moléculas era feita conforme a Figura 1, apenas num plano bidimensional.

${ }^{7} \mathrm{O}$ a plicativo computacional aqui selecionado - Che mSketch - foi em função de ser um dos mais empregados para o ensino de Química, bem como sua fácil funcionalidade. Trata-se de um programa livre que propicia a construção de modelos moleculares bidimensionais e tridimensionais. Maiores informações sobre o programa computacional, bem como o próprio programa para "download", podem ser encontradas em: http://www.acdlabs.com.
}

Página | 257 
modelos (concretos ou computacionais). A partir desta mudança a necessidade da compreensão das estruturas fora do plano do papel passou a ter grande importância no Ensino de Química (2010, p. 28).

Em virtude disso, a representação em 3D não é novidade; o que se apresenta como novo no cenário atual é a simulação computacional que possibilita a interatividade ${ }^{8}$. Eichler e Del Pino (2000) acrescentam que as simulações computacionais possibilitam um ambiente interativo, no qual é possível criar e manipular modelos no espaço em três dimensões. Em consequência, os envolvidos no processo de ensino e de aprendizagem, professor e estudantes, podem construir moléculas e verificar sua geometria molecular ${ }^{9}$ e disposição espacial a partir da rotação delas no espaço tridimensional.

Para isso, vejamos a Figura 3, criada a partir do programa computacional Chemsketck, a qual apresenta isômeros de fórmula molecular $\mathrm{C}_{4} \mathrm{H}_{8}$. As estruturas são representadas considerando a geometria molecular e é exatamente por isso que os átomos de hidrogênio (cor cinza e de menor tamanho) estão afastados dos átomos de carbono (cor azul e maior tamanho).

Figura 3 - Representação tridimensional dos isômeros geométricos: a) cis-but-2-eno; b) trans-but-2-eno.

a)

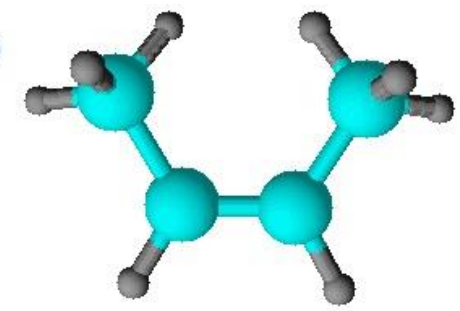

b)

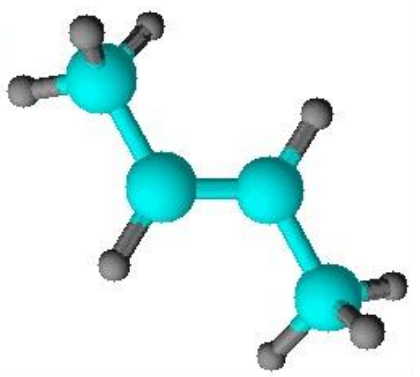

Fonte: Programa computacional ChemSketck (2013)

Em síntese, essa distinção dos átomos que compõem os isômeros é relevante na medida que possibilita uma diferenciação entre os átomos constituintes da molécula. Além disso, este programa educacional propicia nomear as moléculas criadas conforme a IUPAC ${ }^{10}$, como, também, dispõe de um banco de vidrarias e materiais de laboratório que são usados em aulas experimentais. As imagens capturadas no programa computacional ChemSketck apresentam-se aqui de forma estática, mas no ambiente do aplicativo as moléculas podem servisualizadas em constante rotação.

Vejamos agora, como mais um exemplo, a representação molecular da fórmula $\mathrm{C}_{4} \mathrm{H}_{7} \mathrm{C} \lambda$. A representação da fórmula molecular, tomada isoladamente, não permite identificar os isômeros ascendentes dessa representação simbólica. Entretanto, ao visualizar a representação tridimensional dessa estrutura, como

\footnotetext{
${ }^{8} \mathrm{~A}$ interatividade é considerada a capacidade de interação estabelecida por relação recíproca, nesse ca so, é por meio do uso de um progra ma computacional que esse recurso propicia respostas às a ções exercidas. Ferreira (1975) define a interatividade como a capacidade de comunicação recíproca propiciada por um equipamento, programa ou sistema comunicativo permitindo assim a interação. 9 Peculiaridade essa essencial para a compreensão deste conteúdo científico.

${ }^{10}$ A IUPAC é uma organização mundial não governamental que se dedica aos a vanços da Química. A orga nização recebe o nome em língua inglesa: International Union of Pure and Applied Chemistry. Em língua portuguesa representa: União Internacional de Química Pura e Aplicada (tradução nossa). Maiores informações podem ser encontradas no endereço eletrônico da IUPAC. Em: http://www.i upac.org/. Página | 258
} 
mostrado na Figura 4, a diferença entre os isômeros geométricos torna-se bastante evidente.

Figura 4 - Representação tridimensional dos isômeros geométricos: a) cis-3-cloro-buteno; b) trans-3-cloro-2-buteno.

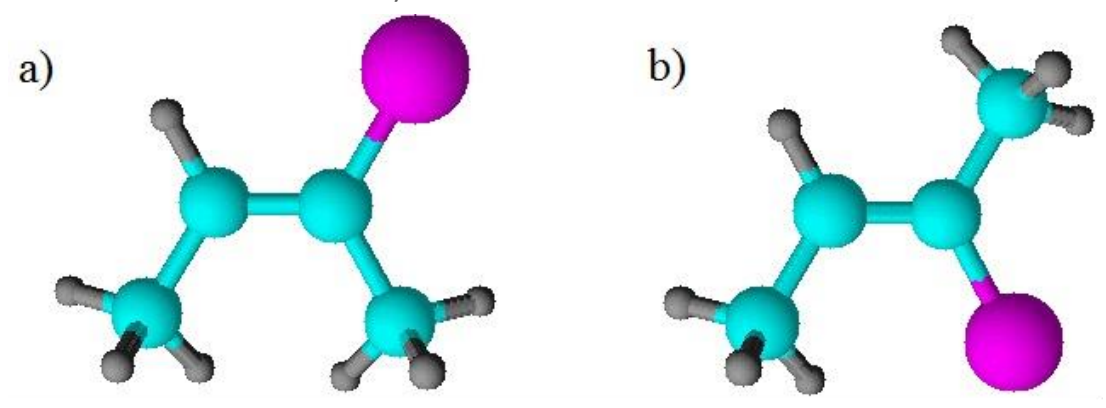

Fonte: Programa computacional ChemSketck (2013)

A visualização tridimensional da estrutura, nesse caso, auxilia a transição do nível simbólico para o nível microscópico, característica essencial para uma aprendizagem mais abrangente e profunda. Mas, como já argumentado, o ensino de Química deve idealmente valorizar todos os três níveis de representação (macroscópico, microscópico e simbólico). Wu e Shah (2004) enfatizam a importância do emprego de uma multiplicidade de representações, pois, quanto mais vastas as formas de representação maiores as condições para a aprendizagem.

Outra vantagem no uso dessas ferramentas digitais é a de que, devido à criação de objetos externos (virtuais) e (ou) a transposição de estruturas bidimensionais para tridimensionais, a internalização das visualizações externas é facilitada sobremaneira; o estudante passa a ter a oportunidade efetiva de manipular mentalmente estruturas, e posteriormente externalizá-las. Raupp, Serrano e Moreira (2009) sublinham essa relevância e eficácia das representações tridimensionais sugerindo que, diante da visualização externa ${ }^{11}$ (promovida pelo programa), seria possível internalizar essas visualizações para então manipular mentalmente estruturas químicas, podendo-se então externá-las, el evando assim a aprendizagem a patamares superiores. Pode-se mesmo afirmar, a partir do exposto, que a visualização é condição essencial à compreensão em Química. Encontramos em Giordan e Góis (2005, p. 289), uma definição precisa acerca do papel da visualização na aprendizagem em Química: "[...] a construção de conceitos está estreitamente relacionada ao formato visual com que os estudantes tiveram contato durante seu aprendizado".

Diante do exposto, encerramos este bloco com a conviç̧ão de que as potencialidades de um programa computacional são significativas, e o uso desses programas computacionais no ensino de Química pode ser um importante diferencial. Passaremos, no próximo bloco, a tratar do estudo de caso.

${ }^{11}$ A visualização externa pode ser promovida a través de a plicativos computacionais, os quais ge ram modelos virtuais e foram aqui criados a partir do programa ChemSketck. Em contra partida, a visualização interna está diretamente ligada com a mente, seria na verda de, a manipulação mental de representações espaciais.

Página | 259 


\section{ESTUDO DE CASO NUMAESCOLA PÚBLICA}

Uma escola da rede pública estadual, localizada na região norte da cidade de Caxias do Sul no estado do Rio Grande do Sul, foi selecionada por ser de grande porte (abrangência), ao mesmo tempo que atende estudantes do Ensino Fundamental e Médio. Conforme Lüdke e André (1986), o estudo de caso busca descrever a realidade de forma profunda e completa de uma determinada situação ou problema, além de enfatizar a compreensão a fundo de um determinado contexto, o que nos levou a realizar entrevistas semiestruturadas com três professores de Química desta escola. Para que pudéssemos analisar as entrevistas sem expor a identidade dos participantes, resolvemos denominá-los de Alfa, Beta e Gama.

A Análise Textual Discursiva (ATD) foi o artefato epistemológico de interpretação dos dados; conforme Moraes e Galiazzi (2011) é uma metodologia que culmina na produção de metatextos analíticos que expressem a descrição e a interpretação do fenômeno que se investigou. As etapas que antecedem a construção de metatextos são a fragmentação e a categorização. A fragmentação consiste na desintegração do "corpus" (grifo dos autores); os textos são desconstruídos e ocorre a unitarização. A categorização é um processo complementar à unitarização. O primeiro - a unitarização - é um movimento de desconstrução, que corresponde a uma análise propriamente dita; o segundo - a categorização - é um movimento de reconstrução em forma de metatextos, que visam expressar novas compreensões alcançadas (MORAES; GALIAZZI, 2011). Seguindo essa dinâmica, emergiram unidades de significado que, agrupadas por semelhança, originaram três categorias: a perspectiva dos professores sobre as tecnologias digitais no ensino de Química, os níveis de representação e as concepções dos professores, e a isomeria geométrica no contexto do Ensino.

\section{A PERSPECTIVA DOS PROFESSORES SOBRE AS TECNOLOGIAS DIGITAIS NO ENSINO DE QUÍMICA}

Os três professores de Química entrevistados avaliam que a única inserção de tecnologia na escola deu-se por meio da implantação do laboratório de informática, mas todos destacaram que este laboratório é um recurso (ambiente) que quase não se explora no ensino da Química. A redução da carga horária dessa disciplina que não implicou numa redução proporcional no conteúdo programático de Química foi o principal motivo apontado pelos três professores. É consenso entre os professores que, em função da baixa carga horária semanal, torna-se inviável levar os estudantes para o laboratório de informática. $O$ depoimento do professor Alfa retrata essa perspectiva "[...] o principal agravante é a falta de tempo, que não permite a gente explorar essas ferramentas [...]". Além disso, os três professores afirmaram que quando levam os estudantes para o laboratório, a finalidade é realizar pesquisas na internet e que em média costumam utilizar o laboratório de informática duas vezes ao ano.

Perguntamos aos professores sobre as possibilidadespor eles imaginadas para o uso das TDs no contexto escolar, especialmente no contexto do ensino de Química. O professor Alfa acredita que os recursos digitais poderiam redirecionar o ensino de Química, caso existissem programas que auxiliassem na rotação das 
moléculas. O depoimento de Alfa revela que ele desconhece os programas computacionais que permitem esses movimentos, além da possibilidade empolgante de representar moléculas em 2D e 3D. Já o professor Beta refere que existem inúmeras ferramentas que permitem visualizar as moléculas se formando, suas quebras, suas formas dimensi onaise geométricas. Apesar de Beta não utilizar nenhum programa computacional para o ensino de Química, reconhece a variedade de aplicativos computacionais existentes na rede e destaca as diversas possibilidades que a internet oferece. No entender do professor Gama, as tecnologias digitais poderiam redirecionar o ensino de Química a partir da possibilidade que os estudantes têm de interagir com esses recursos digitais. Gama tem um blog relacionado ao ensino de Química em geral, como recurso adicional à sala de aula. Nesse blog, complementa os conteúdos trabalhados em aula com exercícios e textos, para que os estudantes se aprofundem mais nos conteúdos. No entanto, Çetin (2016) ao investigar o uso de computadores por professores de Ciências constatou que a maioria deles carece de conhecimentos e habilidade imprescindíveis para o uso de computadores no ensino. Esse fator segundo a autora, faz com que os professores de Ciências empreguem esporadicamente a tecnologia para ensinar.

\section{OS NÍVEIS DE REPRESENTAÇÃO E AS CONCEPÇÕES DOS PROFESSORES}

Questionamos os professores acerca da relevância em fazer a distinção entre os níveis de representação no ensino de Química; os p rofessores Alfa e Betajulgam que essa distinção é necessária. O professor Alfa dizque na escola trabalha-se com os três níveis, admite, porém, que o nível microscópico e o simbólico são os níveis mais explorados no ensino de Química. Já o professor Beta afirmou que costuma relacionar o nível macroscópico com o nível microscópico aplicando-os no cotidiano do estudante, principalmente quando trabalha o conteúdo de estequiometria; nessas ocasiões, faz o estudante pensar o quanto é um $\mathrm{mol}^{12}$ de banana ou um mol de arroz, pois os estudantes "[...] têm que entender que um mol é uma quantidade infinitamentegrande, mas, em outras circunstâncias, pode ser muito pequena" (PROFESSOR BETA).

Quando os professores foram questionados sobre qual dos três níveis seria o mais difícil para o ensino e para a aprendizagem, a resposta foi unânime: o nível microscópico. Na opinião do professor Alfa, o nível microscópico é a forma de representação mais difícil para o estudante aprender, porque "esse é o nível que eles têm que imaginare interpretar". Em continuidade, Alfa diz: "[...] a gente teria que ter alguma coisa que pudesse simular o ensino nos três níveis". Já o professor Gama, com o intuito de promover uma melhor compreensão do nível microscópico por meio de recursos concretos, emprega um material didático chamado "kit de construção de moléculas". Os estudos desenvolvidos por Johnstone (1982; 2000) revelam que existe significativa dificuldade na aprendizagem de Química sobremaneira em decorrência do nível microscópico, mas alerta que o ensino de Química deve valar-se dos três níveis de representação a fim de explorar a capacidade de modelagem e a sucessiva relação entre esses níveis.

12 Pa ra i den tificar o número de partículas em uma amostra, foi criada a grandeza denominada quantidade de matéria, e a unidade de medida é o mol.

Página | 261 


\section{A ISOMERIA GEOMÉTRICA NO ENSINO MÉDIO: A VISÃO DOS PROFESSORES}

Perguntamos aos professores de Química se nos últimos anos eles têm empregado alguma estratégia para ensinar isomeria geométrica ou percebido alguma reformulação no currículo. $O$ professor Beta categoricamente afirmou não ter havido nenhuma mudança na reformulação do currículo e diz que "[...] quanto às estratégias, a gente utiliza todas as armas que dispõe", mas não deixa claro quais seriam. Já o professor Gama relata que faz algum tempo (em torno de 5 anos) que não trabalha com o ensino de isomeria geométrica, mas, quando trabalhava, costumava utilizar um kit de construção de moléculas. Segundo esse professor, a finalidade do emprego desse material didático para o ensino de isomeria é a de que os estudantes conseguem entender com maior facilidade o conteúdo, justamente pela possibilidade de direcionar e visualizar os isômeros no espaço. Vale destacar que a escola possui esse material didático (kit de construção de moléculas) há alguns anos. Gama ressalta que emprega esse material didático desde que atua como professor (há quase 30 anos) e que não se trata de nenhuma novidade ou nova estratégia. Na sua narrativa, Gama menciona que costumava relacionar o conteúdo de isomeria geométrica com o dia a dia dos estudantes, com os tipos de substâncias usadas no cotidiano. Ao final, Gama questiona os pesquisadores se existe algum programa para construir moléculas.

A partir do questionamento desse professor, fizemos uma breve contextualização dos programas disponíveis que permitem a criação de moléculas com precisão de ângulo e com excelente dimensão espacial, informando-o de que estes aplicativos encontram-se gratuitamente na rede mundial de computadores. Também mencionamos a existência de algumas barreiras para o uso desses programas, como, por exemplo: i) a maioria encontra-se no idioma inglês; ii) o sistema operacional deve ser Windows e não Linux ${ }^{13}$. No entanto, na escola cujas entrevistas foram realizadas os dois sistemas operacionais (Windows e Linux) estão disponíveis. É evidente que precisamos desenvolver mais conteúdos e atividades pedagógicas em todos os níveis educacionais a partir da tecnologia digital. Os programas de formação continuada também devem ser direcionados para capacitar os professores e garantir a adoção das TDs no ensino dos conceitos científicos.

Para o professor Alfa o conteúdo de isomeria química está perdendo espaço, em face das diversas realidades visualizadas na escola. Um exemplo disso é que, em decorrência da falta de tempo, tem turmas do terceiro ano do Ensino Médio que nem chegam mais até esse conteúdo, e quando o contemplam, ele é trabal hado apenas em nível de definição e identificação. O professor Alfa explica que nunca empregou a tecnologia digital (nem mesmo pesquisa na internet) para o ensino desse conteúdo. É natural que alguns conceitos quími cos percam espaço devido a redução gradual da carga horária para o ensino de Química nos últimos anos. No entanto, ainda assim, faz-se necessário aos professores tentar explorar as TDs no contexto educacional. Por isso que os programas de formação continuada são tão importantes, pois não basta apenas inserir a tecnologia digital na escola é imprescindível garantir que ela seja adotada de modo efetivo, como

13 Conforme o professor Alfa é comumas escolas públicas possuírem o sistema operacional Li nux por ser gratuito, enquanto que o sistema opera cional Windows é pago. Santos, Wa rtha e Filho (2010) confirmam que a maioria das escolas públicas utiliza o sistema operacional de uso livre (Linux).

Página | 262 
um real instrumento de aprendizagem. Çetin (2016) comprovou que após um programa de desenvolvimento profissional os professores de Ciências desenvolveram habilidades e concepções positivas do emprego dessas tecnologias junto ao ensino.

\section{CONSIDERAÇÕES FINAIS}

A problematização que originou o presente estudo é a que segue: como os recursos tecnológicos digitais (programas computacionais) podem ser usados no ensino de isomeria geométrica? Os recursos tecnológicos digitais, mais especificamente os programas computacionais, podem ser ferramentas decisivas no ensino de isomeria geométrica, pois permitem a construção e visualização de representações de fenômenos químicos que são inacessíveis à percepção humana. Para a compreensão da isomeria geométrica é requisito essencial a manipulação mental das representações espaciais. O estudo realizado por Raupp, Serrano e Moreira (2009) mostra que os estudantes possuem dificuldades em transitar entre os níveis de representação macroscópico, microscópico e simbólico, mas isso é compreensível, dada a natureza inerentemente abstrata da Química. Esses mesmos autores sublinham a relevância da habilidade visuoespacial para transitar entre esses níveis, visto que a mesma é responsável por promover transformações entre as formas de representação bidimensionais e tridimensionais. Diante disso, uma das conclusões de nosso estudo é que o ensino de isomeria geométrica requer fundamentalmente o uso de recursos modernos, tais como os programas computacionais. Justificando a expressão "fundamentalmente", queremos dizer que é na possibilidade de representação das formas abstratas da Química que o uso da tecnologia pode ser decisivo no ensino de isomeria geométrica. Logo, o emprego dessas ferramentas neste ensino tem sima possibilidade de potencializar a aprendizagem dos estudantes, em razão da al ta qualidade das representações tridimensionais que podem emanar dessa exploração, o que promove a visualização das formas abstratas e fomenta inúmeras possibilidades de interação.

Na escola visitada há recursos que permitem o estudo da isomeria geométrica pela via das TDs. Mas o ensino desse conteúdo não se concretiza, pelo menos não nessa escola em que realizamos o estudo de caso, nem com a tecnologia digital e nem sem ela. Os professores apontam como razão principal a "falta de tempo". 0 emprego da tecnologia digital é praticamente nulo em todos os sentidos, visto que o uso da tecnologia restringe-se praticamente a esporádicas buscas na internet. Mas, ainda assim conforme Moran (1997) sublinha: utilizar a internet na educação apoia o ensino na medida em que dilui as barreiras de tempo e espaço, enriquece as possibilidades de emprego de imagens, textos, livros, revistas e programas. Também motiva os estudantes porque "eles gostam de navegar, de descobrir endereços novos, de divulgar suas descobertas, de comunicar-se com outros colegas" (MORAN, 1997, p. 146).

Além disso, o que se evidencia é que os professores desconhecem os programas computacionais que possibilitam, dentre outras coisas, a representação da Química abstrata e a transição entre os níveis de representação do conhecimento químico. Em nenhum momento, no discurso dos professores, cogitou-se a possibilidade de substituir partes do ensino convencional (quadro e 
giz) por estratégias exploratórias, com o uso das TDs. Por exemplo, a construção de modelos moleculares bidimensionais e tridimensionais das moléculas, que inclui a modelização e representação da Química dita abstrata. Nesse sentido, os programas computacionais auxiliariam tanto o estudante quanto o professor na visualização e disposição espacial e geométrica de uma molécula, além do que as simulações computacionais possibilitam um ambiente interativo no qual é possível manipular modelos e obter resultados imediatos, em tempo real (EICHLER; DEL PINO, 2000). Em decorrência, verifica-se um ensino de Química que se volta à exploração quase que exclusiva dos níveis microscópico e simbólico. Essa perspectiva não é novidade, ao contrário, a maioria dos trabalhos especializados na área indica que o ensino de Química nas escolas concentra-se na exploração esses dois níveis, relegando a níveis muito baixos (e mesmonulos) a exploração do nível macroscópico.

Em nosso entendimento, seria valioso os professores explorarem os três níveis de representação do conhecimento químico. Porém, conexões entre o nível macroscópico (como o professor Beta relatou), que é o nível em que o estudante possa identificar a Química no contexto em que está inserido, pode ser o primeiro movimento para construir um ensino de qualidade, isto é, que esteja conectado à realidade dos estudantes. Gabel (1993) destaca ser insuficiente fazer relação entre os níveis de representação no ensino de Química, se os fenômenos estudados não forem relacionados e aproximados à vida cotidiana dos estudantes.

Frente a um ideal de ensino oriundo das ideias de Vygotsky, concepção de ensino que adotamos para olhar o contexto escolar, o cenário hodierno nos fornece evidências desfavoráveis para o exercício dessa concepção, haja vista que, "por enquanto, a aula continua sendo mais tradicional (é o professor quem mais fala)" (PROFESSOR GAMA). Desse modo, a troca mútua entre os participantes do processo de ensino e de aprendizagem fica mais restrita, porque o professor é ainda o elemento central nesse processo. A interação, sem dúvida, é forjada nesse cenário, mas não na amplitude possível e desejável, caso o processo de ensino e de aprendizagem não se concentrasse apenas no discurso do professor. As ferramentas empregadas nesse processo restringem-se às mesmas de décadas atrás: lápis, caneta, cadernos e livros (meios convencionais). Não há nada de fundamentalmente errado com essas ferramentas, mas parece que a escola não evoluiu na medida em que não explora as potencialidades adicionais disponíveis.

Diante disso, pode-se afirmar que, embora os aplicativos computacionais ofereçam grande margem de interação e sejam bem aceitos pelos estudantes, ainda são ferramentas praticamente inexploradas na escola. 


\title{
A case study: computer programs mediating the teaching of geometric isomerism
}

\begin{abstract}
This articleaims to investigate the possibilities of use of computer simulation programs in teaching Chemistry and specifically in the field of geometric isomerism in the context of public education. The study was established from a literature review and a case study in a public school, in which semi-structured interviews were conducted with three teachers of Chemistry. The methodology used was the Textual Discourse Analysis. The results show that the teaching of geometric isomerism can be enhanced with the use of computer applications, a dimension in which the levels of macroscopic, microscopic and symbolic representation are explored from multiple simulations arising in these applications.
\end{abstract}

KEYWORDS: Chemistry teaching. Geometrical isomerism. Computational programs. 


\section{REFERÊNCIAS}

ALMEIDA, M. E. B. de; VALENTE, J. A. Tecnologias e currículo: trajetórias convergentes ou divergentes? São Paulo: Paulus, 2011.

BIANCHETTI, L. Da chave de fenda ao laptop: tecnologia digital e novas qualificações: desafios à educação. Florianópol is: Editora Vozes, 2001.

ÇETIN, N. I. Effects of a Teacher Professional Development Program on Science Teachers' Views about Using Computers in Teaching and Learning. International Journal of Environmental \& Science Education, v. 11, n. 14, p. 8026 - 8039, 2016.

CHARTIER, R. Os livros resistirão às tecnologias digitais. Revista Nova Escola, São Paulo, v. 22, n. 201, p. 22-6, 2007.

EICHLER, M.; DEL PINO, J. C. Computadores em educação química: estrutura atômica e tabela periódica. Química Nova, São Paulo, v. 23, n. 6, p. 835-840, 2000.

FERREIRA, A. B. de H. Novo dicionário da língua portuguesa. 1. ed. Rio de Janeiro: Editora Nova fronteira, 1975.

FERREIRA, C.; ARROIO, A.; REZENDE, D. de B. Uso de modelagem molecular no estudo dos conceitos de nucleofilicidade e basicidade. Química Nova, São Paulo, v. 34, n. 9, p.1661-5, 2011.

FONSECA, M. R. M. da. Completamente química: química orgânica. São Paulo: FTD, 2001.

GABEL, D. L. Use of the particle nature of matter in developing conceptual understanding. Journal of Chemical Education, v. 70, n. 3, p. 193-4, 1993.

GIORDAN, M.; GÓIS, J. Telemática educacional e ensino de química: considerações sobre um construtor de objetos moleculares. Linhas Críticas, Brasília, v. 11, n. 21, p. 285-301, 2005.

JOHNSTONE, A. H. Macro and microchemistry. The School Science Review, v. 64, n. 227, p. 377-379, 1982.

JOHNSTONE, A. H. Teaching of chemistry: logical or psicological? Chemistry Education: Research and Practice in Europe, v. 1, n. 1, p. 9-15, 2000. 
MORAES, M. C. Tecendo a rede, mas com que paradigma? In: MORAES, Maria Candida (org.). Educação a distância: fundamentos e práticas. Campinas, SP: UNICAMP/NIED, p. 1-12, 2002.

MORAES, R.; GALIAZZI, M. do C. Análise textual discursiva. 2. ed. Ijuí: Ed. Unijuí, 2011.

MORAN, J. M. Como utilizar a internet na educação. Revista Ciência da Informação, Brasília, v. 26, n. 2, p. 146-153, 1997.

MOREIRA, M. A. Terias de aprendizagem. 2. ed. São Paulo: EPU, 2011.

NOVAIS, V. L. D. de. Química. São Paulo: Atual, 1993.

OLIVEIRA, S. R.; GOUVEIA, V. de P.; QUADROS, A. L. de. Uma reflexão sobre aprendizagem escolar e o uso do conceito de solubilidade/miscibilidade em situações do cotidiano: concepções dos estudantes. Química Nova na Escola, São Paulo, v. 31 n. 1, p. 23-30, 2009.

PAULETTI, F., CATELLI, F. Tecnologias digitais: possibilidades renovadas de representação da química abstrata. Acta Scientiae, Canoas, v. 15, n. 2, p. 383396, 2013.

PERUZZO, T. M.; CANTO, E. L. do. Química: na abordagem do cotidiano. 1. ed. São Paulo: Moderna, 1996.

Moderna, 2006.

Química na abordagem do cotidiano. 4. ed. São Paulo:

POZO, J. I.; CRESPO, M. Á. G. A aprendizagem e o ensino de ciências: do conhecimento cotidiano ao conhecimento científico. Tradução Naila Freitas. 5. ed. Porto Alegre: Artmed, 2009.

RAUPP, D. T.; SERRANO, A.; MOREIRA, M. A. Desenvolvendo habilidades visuoespaciais: uso de software de construção de modelos moleculares no ensino de isomeria geométrica em química. Experiências em Ensino de Ciências, Cuiabá, v. 4, n. 1, p. 65-78, 2009.

RAUPP, D. T. Um estudo de caso sobre a compreensão de conceitos químicos mediante visualização de representações computacionais 3D utilizando o 
referencial de campos conceituais. 107 f. Dissertação (Mestrado em Ensino de Ciências e Matemática) - Programa de Pós-Graduação em Ensino de Ciências e Matemática, Universidade Luterana do Brasil (ULBRA), Canoas, 2010.

SANTOS, W. L. P. dos; MÓL, G. de S. (coord.). Química e sociedade: volume único, ensino médio. São Paulo: Nova Geração, 2005.

SANTOS, W. L. P. dos; SCHNETZLER, R. P. Educação em química: compromisso com a cidadania. 2. ed. ljuí: Unijuí, 2000.

SANTOS, D.; WARTHA, E. J.; FILHO, J. C. da S. Softwares educativos livres para o ensino de química: análise e categorização. In: XV Encontro Nacional de Ensino de Química-XV ENEQ. Brasília, jul., 2010.

SOUZA, K. A. de F. D. de; CARDOSO, A. A. Aspectos macro e microscópicos do conceito de equilíbrio químico e de sua abordagem em sala de aula. Química Nova na Escola, São Paulo, n. 27, p. 51-6, 2008.

VYGOTSKI, L. S.; LURIA, A. R.; LEONTIEV, A. N. Linguagem, desenvolvimento e aprendizagem. Tradução Maria da Penha Villalobos. São Paulo: Ícone, 2001.

VYGOTSKI, L. S. Pensamento e linguagem. Tradução Jefferson Luiz Camargo; revisão técnica José Cipolla Neto. 2. ed. São Paulo: Martins Fontes, 1998.

WU, H.; KRAJCIK, J. S.; SOLOWAY, E. Promoting understanding of chemical representations: students' use of a visualization tool in the classroom. Journal of Research in Science Teaching, v. 38, n. 7, p. 821-842, 2001.

WU, H.; SHAH, P. Exploring visuospatial thinking in chemistry learning. Science Education, v. 88, n. 3, p. 465-492, 2004. 
Recebido: 2017-03-30

Aprovado: 2017-06-13

DOI: $10.3895 /$ rbect.v11n1.5759

Como citar: PAULETTI, F.; CATELLI, F. Um estudo de caso: programas computacionais mediando o ensino de isomeria geométrica. Revista Brasileira de Ensino de Ciência e Tecnologia, v. 11, n. 1, 2018. Disponível em:

<https://periodicos.utfpr.edu.br/rbect/article/view/5759>. Acesso em: xxx.

Correspondência: Fabiana Pauletti -fpaulet1@ucs.br

Direito autoral: Este artigo está licenciado sob os termos da Licença Creative Commons-Atribuição 4.0 Internacional.

\section{(c) (i)}

